
Military Technical College Kobry El-Kobbah, Cairo, Egypt.

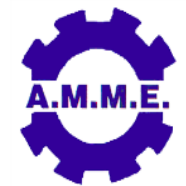

\title{
INFLUENCE OF SOLIDIFICATION RATE ON ELECTRICAL AND MECHANICAL PROPERTIES OF EUTECTIC AND HYPEREUTECTIC AL-SI ALLOYS
}

\author{
M. M. Meiz ${ }^{1}$, M. S. El-Wazery², S. M. Khafagy ${ }^{3}$ and R. A. Elsad ${ }^{4}$
}

\begin{abstract}
Eutectic Al-13 wt. \% Si and hypereutectic Al-16 wt. \% Si were prepared by using permanent mould casting technique. Effect of the cooling technique on the cast microstructure, mechanical properties, and electrical conductivity of Al-Si alloys was investigated by using the conventional water-cooled and air-cooled methods. The mechanical properties such as the yield stress, tensile strength, hardness, and impact energy were measured at various cooling methods. Microstructure with scanning electron microscope (SEM) and Energy dispersive spectrometer (EDS) analysis of Al-Si alloys have been studied. In addition, the hardness after solution treatment at $529{ }^{\circ} \mathrm{C}$ for $2 \mathrm{~h}$ and artificial ageing at various temperatures $180{ }^{\circ} \mathrm{C}$ and $210^{\circ} \mathrm{C}$ for aging time $2-10 \mathrm{~h}$ was measured. The results show enhancement in the mechanical and electrical properties for the eutectic Al-13 wt. \% Si and hypereutectic $\mathrm{Al}-16$ wt. \% Si alloys for the water-cooled over the air-cooled technique. In addition, the largest value of the impact energy $(4.91 \mathrm{~J})$ was obtained for the eutectic Al-13 wt. $\% \mathrm{Si}$ alloys compared to the hypereutectic Al-16 wt. \% Si alloys at $3.09 \mathrm{~J}$ for watercooled-medium. The total solidification time (TST) of Al 13\% wt. Si was longer than that time for the hypereutectic Al $16 \%$ wt. Si at various cooling mediums. Aging studies of $\mathrm{Al}-\mathrm{Si}$ alloys with aging temperatures $180^{\circ} \mathrm{C}$ and $210^{\circ} \mathrm{C}$ show that the hardness values increased as the silicon content increases. For hypereutectic Al-16 wt. \% Si at aging temperature $180{ }^{\circ} \mathrm{C}$ and aging time $4 \mathrm{~h}$ by using water-cooled technique, it was observed that the maximum hardness value reached to $100 \mathrm{HRD}$ compared that value was $87 \mathrm{HRD}$ for the eutectic Al-13 wt. \% Si alloy.
\end{abstract}

\section{KEYWORDS}

Hypereutectic Al-Si, Permanent mould casting, Mechanical properties, Electrical conductivity, Artificial ageing.

1 Graduate student, Production Engineering and Mechanical Design Department, Faculty of Engineering, Minoufia University, Shebin El-Kom, Egypt.

2 Lecturer, Production Engineering and Mechanical Design Department, Faculty of Engineering, Minoufia University, Shebin El-Kom, Egypt. Email: eng_mahmoudsamir@yahoo.com.

3 Associate Professor, Tabbin institute for metallurgical studies, Cairo, Egypt.

4 Lecturer, Basic Science Department, Faculty of Engineering, Minoufia University, Shebin El-Kom, Egypt. 


\section{INTRODUCTION}

Al-Si Alloys normally consisting of the single element phase (silicon) in the eutectic matrix form and were distinguished according to the silicon concentration into three categories: Hypoeutectic containing (5-10\% Si), Eutectic containing $(11-13 \% \mathrm{Si})$, and hypereutectic containing (14-25\% Si). The hypereutectic alloys are more wearresistant than the hypoeutectic alloys and the wear resistance increases with the increasing in silicon content during casting. These alloys were especially used in automotive pistons and engine block, valve lifters, pumps, compressors, manufacture of tools, power translation line, and electrical industries because of the high temperature strength, high electrical conductivity, and excellent wear resistance [1-6]. The mechanical properties and microstructure of hypereutectic alloys depend on the casting process and solidification rate, so the solidification rate was considered one of the most important variables. A good casting process is to fill the mould cavity without any defects [7]. Currently the permanent mould casting (PM) technique considers one of the commercially feasible technologies for production of high integrity, complex shaped with improved mechanical properties and surface finished [8]. The solidification and mechanical properties of Al-Si alloys were investigated. It was found that the solidification time increased as the silicon concentration increased, also the mechanical properties such as, the hardness value increase up to $70 \mathrm{MPa}$ with the increasing in silicon content at $12 \% \mathrm{Si}$ and decreases to $60 \mathrm{MPa}$ at $15 \%$ Si content [9].

Effect of cooling rate on mechanical properties of eutectic and hypoeutectic Al-Si alloys was demonstrated. The pouring in a permanent mold of these alloys gives large strength and impact resistance when compared to the pouring in the sand mold [10]. Wiechec et al. [11] studied the effect of silicon content and heat treatment on the electrical conductivity and mechanical properties of hypereutectic alloys. It has been concluded that the best hardness properties for the tested alloys obtained with the heat treatment (T6), at the temperature of $180{ }^{\circ} \mathrm{C}$ and the ageing time of 2 to 8 hour. Singh et al. [12] investigated the microstructure and mechanical properties of Al-Si Alloy under heat treatment conditions (T6). The hardness value of this alloy with heat treatment condition was $65.98 \mathrm{Hv}$. The effect of silicon concentration at 5, 7, 9, 12.5 and $14 \%$ on mechanical properties of Aluminum alloy was demonstrated. Yield strength, ultimate tensile strength and the hardness increases with the increasing in silicon concentration at various contents but the elongation decreases [13]. In addition, Chen [14] investigated the distribution of $\mathrm{Si}$, microstructure and hardness of hypereutectic Al-18wt. \% Si Alloy by using centrifugal casting technique. The hardness of this alloys increased with the increasing in Si content. After solution treatment (T6), the casting hardness will increase slightly.

Zeren [15] demonstrated the mechanical properties of Al-Si-Cu alloys. The solution treatment of this alloy was carried at $500{ }^{\circ} \mathrm{C}$ for $7 \mathrm{~h}$ and aged at $190^{\circ} \mathrm{C}$ for $15 \mathrm{~h}$. The improvement in mechanical properties is depending on the variation of the size of the eutectic silicon phase particles. Electrical conductivity, microstructures, and aging conditions were discussed. Electrical conductivity shows an upward trend compared to with the aging time. Aging causes the Si precipitates in this alloy to cluster tightly together and allowing an electrical signal to easily propagate through it [16]. Hossain and Kurny [17] studied the effect of artificial ageing at various temperatures on the mechanical properties of Al-Alloys. The yield stress and ultimate tensile strength increased with ageing temperature increased up to $225^{\circ} \mathrm{C}$. As the ageing 
temperature increases from room temperature to $225^{\circ} \mathrm{C}$, the absorbed energy decreases for all the alloys. The effect of artificial aging on the strength and electrical conductivity of AlSiMg aluminum alloys were investigated. The hardness and electrical conductivity increased as the silicon percent increases [18].

Perez et al. [19] study effect of the electrochemical parameter combined with mechanical properties and grain refinement of Al- Me alloy. Mechanical properties especially yield tension stress, and micro-hardness Vickers was improved for high cooling rate. The effect of temperature and cooling rate on the microstructure of Al$18 \% \mathrm{Si}$ was investigated. It was found that the cooling rate reaches a maximum value to $5^{\circ} \mathrm{C} / \mathrm{s}$; and hardness value rises to 51.97 (HRA) [20]. Kumar et al. [21] studied effects of heat treatment on tensile, impact strength and hardness of the Al-Si alloys. The results show the hardness increases with an increase in silicon amount, while the impact strength decreases with the increasing in silicon content.

The objective of this paper is to declare the effect of the cooling medium on the mechanical, electrical properties and the microstructure of eutectic Al-13 wt. \% Si and hypereutectic Al-16 wt. \% Si at various cooling techniques. The solution treatment was carried with artificial ageing (T6) on mechanical properties such as digital Rockwell hardness (HRD) at various ageing temperatures $180{ }^{\circ} \mathrm{C}$ and $210 \stackrel{\circ}{\circ} \mathrm{C}$ for ageing time from 2 to 10 hours.

\section{EXPERIMENTAL PROCEDURE}

Al-Si alloys with composition (13 and 16 wt. percentage Si) were prepared by using the permanent mould casting technique (PMC). The chemical composition of the experimental Al -Si Alloys was listed in Table 1.

The melt was poured into a copper crucible whose size was $200 \times 150 \times 15 \mathrm{~mm}^{3}$ in an electrical resistance furnace at $800 \stackrel{\circ}{ } \mathrm{C}$. Then, the pure silicon was added to the melt for having the Al-Si alloys (13 and 16 wt. \%). In addition, the melt was stirred for 3 minutes after the addition of the silicon. Three K-type NiCr thermocouples were stuck in three areas of different sections to record the temperature as a function of time during the solidification and that is enable to record the temperature up to $1000{ }^{\circ} \mathrm{C}$, Fig.1. The charge material was melted and pouring was performed manually, the corresponding curves for cooling rate were obtained. Several series of samples were prepared and then exposed to different cooling methods: water-cooled and aircooled.

The solution treatment was composed of heating at $529{ }^{\circ} \mathrm{C}$ for $2 \mathrm{~h}$ and then quenching in water at room temperature. The sample were aged at various temperatures $180{ }^{\circ} \mathrm{C}$ and $210{ }^{\circ} \mathrm{C}$ for ageing time from 2 to 10 hours to study the aging effect on the hardness of these alloys. The solution treatment and aging diagram of $\mathrm{Al}-\mathrm{Si}$ alloys are shown in Fig. 2. Five readings of the hardness were performed for each specimen at $180^{\circ} \mathrm{C}$ and $210^{\circ} \mathrm{C}$ of this alloys.

The porosity level of Al-Si alloys with composition (13 and 16 wt. percentage silicon) at water and air-cooled technique was calculated by Eqn.(1) after determining the actual density and the theoretical density of this alloys for five specimens by using the water immersion method (Archimedes method) [22]. 


$$
\text { Porosity }=\left(1-\frac{\rho_{a c t}}{\rho_{t h}}\right) X 100
$$

where, $\rho_{\text {th }}, \rho_{\text {act }}$ are the theoretical and actual density.

The electrical conductivity was carried to observe the effect the cooling medium such as water-cooled and air-cooled methods on the electrical behavior of these alloys. Electrical conductivity of the investigated samples was measured by source meter (KEITHLEY Series 2600A). The Lab VIEW-based software used to measures 15 times of electrical conductivity during $10 \mathrm{~s}$ and then records the average value. The software has been used to transfer the digitalized data from the source meter simultaneously using IEEE-488 (GPIB). If the resistance of wiring and contacts of cell are in the same order of magnitude as the sample resistance, a two terminal measurement will produce huge errors. A significant improvement was optimized by using 4-wire remote sense connections as shown in Fig.3. When sourcing voltage, 4wire remote sensing ensures that the programmed voltage was delivered to the sample only.

Tensile properties of these alloys at various cooling methods were studied by using the universal testing machine (TQSM 1000), according to ASTM D638 standard with dimensions $165 \mathrm{~mm}$ length, $19 \mathrm{~mm}$ width and $5 \mathrm{~mm}$ thickness, Fig.4. The tensile test was carried at room temperature at crosshead speed of $2 \mathrm{~mm} / \mathrm{min}$.

The hardness tests of all the samples have been done using a digital Rockwell hardness tester (HRD) on D scale by steel ball indenter $1.58 \mathrm{~mm}$ diameter with a 15 $\mathrm{kg}$ load at time of $20 \mathrm{sec}$. For each composition of the two alloys $A$ and $B$, six indentations were recorded then taken the average value. The toughness of these alloys was determined by using the standard charpy $\mathrm{V}$-notched tester to observe the impact strength of the Al-Si alloys. The specimens have a square cross-section of side $15 \mathrm{~mm}$ and length $50 \mathrm{~mm}$, crack depth is $2 \mathrm{~mm}$. The microstructures of the experimental alloys were examined at room temperature by using scanning electron microscope (SEM-Jeol 6060).

\section{RESULTS AND DISCUSSIONS}

\section{Solidification Rate}

Figure 5 shows the cooling curve of the experimental Al-13 wt. \% Si and Al-16 wt. \% Si alloys by using an air cool and cold water-cool. Cooling curves were constructed using the temperature-time data obtained with the thermocouples during the permanent mould casting technique. Temperatures of the liquidus and solidus of this alloys line can be determined from the typical cooling curves, Fig.5. The eutectic temperature of $\mathrm{Al}-13$ wt. \%Si and $\mathrm{Al}-16$ wt. \% Si alloys were $570.40{ }^{\circ} \mathrm{C}$ and $563{ }^{\circ} \mathrm{C}$ for air-cooled, while at $564.3^{\circ} \mathrm{C}$ and $546{ }^{\circ} \mathrm{C}$ for water-cooled, respectively. In addition, the total solidification time (TST) of hypereutectic Al-16 wt. \% Si alloys was longer than the $\mathrm{Al}-13 \mathrm{wt}$. \% Si alloys at various cooling rates. The total solidification time of Al 13 wt. \% Si was $40 \mathrm{sec}$ and $59.6 \mathrm{sec}$ in water and air-cooled method, while the total solidification time of hypereutectic Al 16 wt. \% Si was $55 \mathrm{sec}$ and $70 \mathrm{sec}$, respectively. Cooling rate and liquid as temperature, and total solidification time (TST) increased as the silicon content is increased. This is due to the increase in nucleation rate of primary silicon so the cooling rates increased as the nucleation 
undercooling increases. The shape and grain size of primary silicon affect the nucleation rate and the solidification rate [23]. The use of water-cooled technique decreased the size of the primary silicon grains, with the consequent decreased in the rate of nucleation in hypereutectic of the Al-Si alloys so the water-cooled has caused the molten metal to cool faster than air-cooled technique, and produced finer and non-dendrite primary silicon grains at hypereutectic compared to the air cooled medium. The minimum interval of the phase transformation from liquid to solid state of $\mathrm{Al}-13$ wt. \% Si alloys occurred in water-cooled and reached to 40 sec compared to air-cooled medium at $59.60 \mathrm{sec}$, where the solidification rate in water-cooled is faster than the air-cooled methods. The local solidification time (LST) of hypereutectic Al-16 wt. \% Si was $12 \mathrm{sec}$ for water and air-cooled medium.

\section{Density Measurements and Electrical Conductivity}

Table 2 shows the density, the porosity ratios and electrical conductivity measurements of $\mathrm{Al}-13 \% \mathrm{Si}$ and hypereutectic $\mathrm{Al}-16 \% \mathrm{Si}$ alloys at various cooling mediums. As seen in this table, the hypereutectic Al-16\% Si alloys exhibited lower porosity ratios reached to $1.17 \%, 1.60 \%$ compared to the eutectic Al- $13 \%$ Si alloys at $2.22 \%, 3.10 \%$ for water and air-cool, respectively. The increase in the silicon content of Al-Si alloys after reduces the porosity levels. In addition, the porosity levels of Al-Si alloys in case of water-cooled was lower than that in cause of air-cooled medium. This is due to the lowest TST for water-cooled medium, which decrease the percentage of porosity. However, there is no addicted time for accumulation of the gas porosity, where the gas porosity couple with shrinkage porosity was producing the dimples and cavities as shown in the microstructure of eutectic Al-13\% Si alloys by using air-cooled medium. Therefore, the porosity levels were high in air-cooled technique at the highest TST.

The electrical conductivity for Al alloy with two silicon concentration and two cooling mediums is illustrated in Table 2. Generally, the data reflect that for both cooling technique there are a decrease in the electrical conductivity with increasing silicon content. The recorded electrical conductivity values for water-cooling are higher than those for air-cooling as can be clearly seen from Table 2. Electrical conductivity of Alalloys was reduced by metallic additions. All known silicon additions to Al-alloys reduce its electrical conductivity has been attributed the resistivity of silicon is higher than that of $\mathrm{Al}$ [24]. The steady decrease of electrical conductivity during air-cooling than water-cooling has been attributed by many investigators because of gradual increase in the number and size of a very fine and coherent precipitates, called Guinier-Preston (GP) zones. It has been well documented that the G.P. zones are very effective in dispersing electrons, prompting the abatement in the electrical conductivity of the matrix. This electron scattering effect was induced by the coherent strains related with the G.P. zone precipitates.

\section{Mechanical Properties and Cast Microstructure}

The tensile stress- strain curves of water-cooled and air-cooled of an Al Alloys (13 and $16 \%$ wt. Si) are shown in Fig 6 . The hypereutectic alloy with 16 wt. \% Si by water-cooling has maximum tensile and yield strength of $148 \mathrm{MPa}, 100 \mathrm{MPa}$, respectively as compared to the Al alloy with 13 wt. \% Si of $123 \mathrm{MPa}$ and $90 \mathrm{MPa}$ at the same cooling condition. This is because of the group of interactions factors including variations of the solidification rate and the eutectic composition, the shape 
and distribution of primary silicon and eutectic structure of $\alpha-\mathrm{Al}$ and $\mathrm{Si}$ at the hypereutectic. The increase in the silicon amount leads to improve the mechanical properties such as young modulus, tensile strength and hardness of the hypereutectic Al-16 Si alloys, also enhanced the castability, fluidity and decreased hot tearing defects in there alloys. Furthermore, the increase in silicon content, the cooling rates of $\mathrm{Al}-\mathrm{Si}$ alloys intense the nucleation of primary grains at hypereutectic increases leads to grain refinement.

The tensile strength of air-cooled $\mathrm{Al}-13 \mathrm{wt}$. \% Si alloys was smaller than that for water-cooled alloys. The decresing in the tensile strength of this alloy was mainly attributed to the formation of fine grains and dimples in the microstructure. Otherwise, the total elongation ratio of hypereutectic Al-16 wt. \% Si has lower and reaches to $3.53 \%$ and $3.10 \%$ for water and air-cooled medium, respectively compared to these values of eutectic Al-13 wt. \% Si at $4.35 \%, 3.90 \%$, respectively, Table. 3 . It is due to the increasing in volume fraction of silicon-based phases in the soft and ductile matrix of aluminum, which decreases the cavitation resistance of the aluminum matrix and leads to micro cracking in aluminum matrix. In addition, the hypereutectic $\mathrm{Al}-16 \mathrm{wt}$ \% $\mathrm{Si}$ alloy has coarse primary silicon and eutectic structure because of the brittle form of the hard phase so the ductility decreased than Al-13 wt. \% Si alloys which contains more nucleation of $\mathrm{Al}$ dendritic grains at eutectic structure under different cooling rates.

The Rockwell hardness number of the Al-13 wt. \% Si and hypereutectic Al-16 wt. \% $\mathrm{Si}$ alloys are listed in Table.3. The maximum hardness number was $84 \mathrm{HRD}$ of the hypereutectic $\mathrm{Al}-16$ wt. \% Si alloys compared to the hardness of $\mathrm{Al}-13$ wt. \% Si alloys was $72 \mathrm{HRD}$ under water-cooled medium. In addition, the minimum hardness values it observed for the Al-13 wt. \% Si and hypereutectic 16 wt. \% Si alloys at air-cooled medium. The hardness values of the Al-Si alloy increase with the increasing silicon content in aluminum matrix at different cooling rates, where the primary silicon was very harder phase than aluminum matrix in hypereutectic structure. In addition, the increase in liquids temperature and the solidification rate resulted the coarse and dendrite primary silicon grains at hypereutectic structure. The dendrite silicon grain structure gives the high hardness of Al-16 wt. \% Si alloys.

Figure 7 shows the impact energy of the $\mathrm{Al}-13$ wt. \% Si and hypereutectic $\mathrm{Al}-16 \mathrm{wt} . \%$ $\mathrm{Si}$ alloy at various cooling techniques. The maximum impact energy for Al- $13 \% \mathrm{Si}$ at water-cooled method was $4.91 \mathrm{~J}$ while the minimum impact energy was for hypereutectic Al- 16 wt. \% Si at air-cooled methods (3.09 J). The variation in impact energy values shows that impact energy decreases with an increasing in silicon content in Al-Si Alloys. The impact energy was inversely proportional with the hardness, where the increase in silicon content leads to a decrease in impact energy or toughness. In addition, the dispersing of hard primary silicon in $\mathrm{Al}$ matrix decreases the absorption energy of this alloy. The decresing in impact energy of $\mathrm{Al}$ 16 wt. \% Si alloys, it is attributed to the high hardness of the coarse primary silicon particles in hypereutectic structure, they are brittle and easy to crack initiation and fracture over the soft Al matrix where the Al matrix absorbs the impact energy. In addition, the impact energy value reaches to $4.91 \mathrm{~J}$ in case of water-cooled medium of the eutectic Al-13 wt. \% Si alloys, while the impact values was $3.86 \mathrm{~J}$ in case aircooled at of the same alloy. This increase in the impact energy of this alloy is due to the fast cooling of the molten metal, where the TST of the this alloys in water-cooled medium was $40 \mathrm{sec}$ but the TST in air-cooled medium reaches to $59.60 \mathrm{sec}$. 
Figure 8 presents the micrographs examined by SEM with EDS analysis of the eutectic $\mathrm{Al}-13 \mathrm{wt}$. \% Si alloys for the air-cooled medium produced by permanent mould casting technique. As can be seen from the Fig.8a, the silicon crystals were uniformly distributed in the aluminum matrix but their size is not refined. In addition, the level of porosity is relatively high and reached to the $3.93 \%$ in Al-13 wt. \% Si alloy compared to minimum value at $2.81 \%$ for the Al-16\% Si alloys. The shrinkage and big gas pores (cavities) composited at the interfaces between the Al matrix and $\mathrm{Si}$ crystals are the main reason for the decrease in the mechanical properties of $\mathrm{Al}-13$ wt. \% Si was attributed to the weak interfacial bonding Al matrix and Si particles. In addition, it was found that a little micro-crack was observed in Si crystals (Fig.8b). This shows that the fracture was ductile, soft in the Al matrix, and hard, brittle in the Si crystals. This is because of the low ductility of the hard silicon crystals. EDS analyzed the chemical composition of the grain area of Al-Si alloys.

EDS analysis of $\mathrm{Al}-13 \mathrm{wt}$. \% Si alloys indicated the normal weight percent's and atomic ratios of the silicon phase in the Al matrix according to two assigned points (point $A$ and point $B$ ) and are shown in Fig.8c,d. It is obvious that for assigned point $A$ the atomic percent of the Si and Al elements was $21.85 \%$ and $78.17 \%$, respectively while for point $\mathrm{B}$, the atomic percent of $\mathrm{Si}$ and $\mathrm{Al}$ was $81.45 \%, 18.55 \%$. SEM of the hypereutectic $\mathrm{Al}-16 \% \mathrm{Si}$ by using the water-cooled medium is shown in Fig.9. Eutectic was the mixture of Al and Si phase and combined because of the nucleation of silicon crystals during solidification. Moreover, it can be shown from Fig.9a, eutectic silicon particles were homogeneously distributed in the grain boundary.

The formation of the eutectic silicon was very fine in case of water-cooled over that the air-cooled. This is because the short TST of Al-16 wt. \% Si for water-cooled compared with that for air-cooled. In addition, the hard primary silicon crystals were surrounded by the eutectic structure. The formation of porosity in the hypereutectic $\mathrm{Al}-16$ wt. \% Si alloys was depends on the eutectic solidification. However, it was observed that there were little pores of the hypereutectic Al-16 wt. \% Si at the interface as shown in Fig.9b compared to more pores in the eutectic $\mathrm{Al}-13 \mathrm{wt}$. \% Si at the same cooling medium.

\section{Ageing Temperature and Hardness Variation}

Figure.10 develops the hardness varieties with ageing time at $180{ }^{\circ} \mathrm{C}$ (Fig.10a), 210 ${ }^{\circ} \mathrm{C}$ (Fig.10b) for eutectic and hypereutectic Al-Si alloys. The data are given in Table 4. The hardness at ageing temperature $180^{\circ} \mathrm{C}$ and $210^{\circ} \mathrm{C}$ increased with silicon content increases at ageing time from 2-10 hours. This is because the good interfacial bonding strength of eutectic phase after ageing. It was observed that the variation in hardness values of $\mathrm{Al}-\mathrm{Si}$ alloys depends on the aging temperature and ageing times. The maximum hardness was recorded $100 \mathrm{HRD}$ for Al-16 Si alloys, $180{ }^{\circ} \mathrm{C}$ aging temperature at time $4 \mathrm{~h}$ utilizing water-cooled technique compared to this value of eutectic $\mathrm{Al}-13 \mathrm{Si}$ was $87 \mathrm{HRD}$ at the same conditions and as shown in Fig.10a. In addition, the hypereutectic Al-16 Si alloys at aged $180^{\circ} \mathrm{C}$ and watercooled medium, the hardness value increased as the aging time increases reached to maximum value at $100 \mathrm{HRD}$ up to $4 \mathrm{~h}$ and then dropped gradually to minimum value at $89 \mathrm{HRD}$ for $10 \mathrm{~h}$. It was noted that the hardness value increases with the increasing aging time up to a certain limit that depends on the eutectic composition and aging temperature of these alloys. 
As the seen in Fig.10b, at the $210{ }^{\circ} \mathrm{C}$ aging temperature, the hardness values of eutectic $\mathrm{Al}-13 \% \mathrm{Si}$ and hypereutectic $\mathrm{Al}-16 \% \mathrm{Si}$ alloys at air and water-cooled show a decrease over ageing time from 2-10 $\mathrm{h}$ compared to this values at ageing temperature $180^{\circ} \mathrm{C}$. The decrease in hardness values while ageing at $210^{\circ} \mathrm{C}$ was attributed to the over-aging of the Al-Si alloys. Therefore, it can be observe that the aging at temperature $210^{\circ} \mathrm{C}$ for ageing times from 2- 10 hours has a poor effect on the Rockwell hardness values of Al- Si alloys, while ageing at $180{ }^{\circ} \mathrm{C}$ has a benifitable effect on the Rockwell hardness values at various cooling techniques.

\section{CONCLUSIONS}

- The porosity ratio for the hypereutectic $\mathrm{Al}-16 \mathrm{wt}$ \% $\%$ Si alloys was lower than that the $\mathrm{Al}-13 \mathrm{wt}$ \% $\mathrm{Si}$ alloys. In addition, the porosity ratio increases with using the air-cooling than the water-cooling method.

- The values of the tensile strength, yield stress and the hardness for the hypereutectic Al-16 wt. \% Si was greater than that values of the eutectic alloy Al13 wt. \% Si) at various cooling mediums.

- The total elongation ratio of Al-Si alloys decreases but the Rockwell hardness value increases with an increasing in the silicon content.

- Microstructure of $\mathrm{Al}-13 \mathrm{wt}$ \% Si alloys by using the air-cooled medium shows little micro-cracks and cavities at the interface between the Al matrix and silicon phase.

- The electrical conductivity for $\mathrm{Al}-16 \% \mathrm{Si}$ alloys was lower than that the $\mathrm{Al}-13 \% \mathrm{Si}$ alloys. In addition, the electrical conductivity enhances with using the watercooled than air-cooled techniques.

- Aging at $180{ }^{\circ} \mathrm{C}$, gives maximum hardness values of the eutectic and hypereutectic Al-Si alloys at different cooling mediums within ageing time 4 hours compared to the ageing at temperature $210^{\circ} \mathrm{C}$ and the same ageing time.

\section{REFERENCES}

[1] S. Nikanorov, V. Peller, G. Totten, D. Mackenzie, (Eds.), "Handbook of Aluminum, Physical Metallurgy and Processes", Vol.1, Marcel Decker, New York, pp.81-211, 2003.

[2] J. S. Skrzypek, K. Przybyłowicz, "Metals and alloys engineering", (Eds.), AGH, Kraków, 2012.

[3] H. Ye, "An Overview of the Development of Al-Si Alloy Based Material for Engine Applications", J. of Mater. Eng.\& Perf., Vol. 12, No. 3, pp. 288-297, 2003.

[4] J. Kaufman, E. L. Rooney, "Aluminium Alloy Castings, Properties, Processes and Application", American Foundry Society, 2004.

[5] N. S. Grigoriev, N. A. Krasnovskii, "Study of The Triboengineering Characteristics of Ultra-Dispersed Composite Powder Materials", J. of Fricti. \& Wear, Vol. 32, No. 3, pp.164-166, 2011.

[6] F. Kiessling, P. Nefzger, F. Nolasco, U. Kaintzyk, "Overhead Power Lines: Planning, Design, Construction", Springer, Berlin, 2003.

[7] J. Jorstad, D. Apelian, "Hypereutectic Al-Si Alloys: Practical Casting Considerations", Int. J. Met. Cast., Vol. 3, No. 3, pp.13-36, 2009. 
[8] K. P. Rohatgi ASM Handbook, Casting, Materials Parks, Ohio, ASM International Vol.15, pp.1149- 1153, 2008.

[9] G. Abdel-Jaber, A. M. Omran, K. A. Khalil, M. Fujii, M. Seki, A. Yoshida, "An Investigation into Solidification and Mechanical Properties behavior of Al-Si Casting Alloys" Int. J. of Mech. \& Mechatr. Engin. IJMME-IJENS, Vol. 10, No. 4, pp.30-35, 2010.

[10] D. Zeyad, D. Kadhim, "Effect of cooling rate on mechanical properties of eutectic and hypoeutectic Al-Si alloys", J. of Engin., Vol. 17, pp.1576-1583, 2011.

[11] J. Wiecheć, P. Uliasz, T. Knych, M. Piwowarska-uliasz, R. Jarosz, "The Influence Of Chemical Composition And Parameters of Heat Treatment on The Mechanical Properties and Electrical Conductivity In Hypoeutectic Aluminum Silicon Alloys", Archiv. of found. Engine., Vol 13, No. 3, pp.179-184, 2013.

[12] R. Singh, A. Telang, S. Das, "Microstructure and Mechanical Properties of Al-Si Alloy in as Cast and Heat Treated Condition", Ameri. J. of Engin. Rese. (AJER), Vol. 5, No. 8, pp.133-137, 2016.

[13] M. Kalhapure, P. Dighe, "Impact of Silicon Content on Mechanical Properties of Aluminum Alloys", Int. J. of Scie. \& Res. (IJSR), Vol 4, No. 6, pp. 38-40 June 2015.

[14] Z. Chen, Y. Su, S. Gong, "Effect of Centrifugal Casting on Microstructures and Properties of Hypereutectic Al-18wt.\%Si Alloy", Int. Foru. on Energ, Enviro. \& Sustain. Develop., (IFEESD), pp. 706-710, 2016.

[15] M. Zeren, E. Karakulak, S. Gümüş, "Influence of Cu Addition on Microstructure and Hardness of Near-Eutectic Al-Si-Xcu-Alloys", Nonferr. Met. Soc. China, Vol. 21, pp.1698-1702, 2011.

[16] L. George, B. Charles, P. Ruiz, X. Wang, "Thermal and Electrical Transport Measurements in Wrought and Cast Aluminum Alloys", Project Degree of Bachelor of Science, April 30, Worcester polytechnic institute, pp.1-61, 2015.

[17] A. Hossain, A. Kurny, "Effect of Ageing Temperature on the Mechanical Properties of Al-6Si-0.5Mg Cast Alloys with Cu Additions Treated by T6 Heat Treatment", Unive. J. of Mater. Sci. Vol. 1, No. 1, pp.1-5, 2013.

[18] T. Knych, J. Wiecheć, P. Uliasz, "Development of Strength and Electrical Properties of Al-Si-Mg Casting Aluminum Alloys With An Mg Content Of 1 Wt\%", Metall. \& Found. Engi. , Vol. 42, No.1, pp. 47-56, 2016.

[19] O. Pérez, O. Sotelo, M. Vázquez, S. Valdez, "The Electrochemical Behavior and Heat Removal Study during the Solidification Process of an Al-base Alloy", Int. J. Electrochem. Sci., Vol.12, pp.733 -746, 2017.

[20] C. El Akili, M. Alami, A. Bouayad, "Cooling Rate Effect Study on the Microstructure and Hardness of Hypereutectic Aluminum Al-18\%Si Elaborated by V-process", Int. J. of Eng. Trend. \& Technol. (IJETT), Vol. .7, No. 2, pp. 65.69, 2014.

[21] N. kumar, S. Soni, R. Rana, "Mechanical Properties Enhancement of Al-Si (ADC12) Alloy by Heat Treatment". Int. J. of mech. \& product. Engine., Vol. 5, No.1, pp.2320-2092, 2017.

[22] M. Philip, and B. Bolton, "Technology of Engineering Materials", First edition, pp. 46, 2002.

[23] H. Budiman, Z. M. Omar A. Jalar, G. A. Jaharah, "Effect of Water Cooling on The Production of Al-Si Thixotropic Feedstock By Cooling Slope Casting". Europ. J. of Scien. Res., Vol. 32, No. 2, pp. 158-166, 2009. 
[24] H. M. Mulazimoglu L. A. Drew E. J. Gruzelski "Electrical Conductivity of Aluminum-Rich Al-Si-Mg Alloys ", J of Mater. Sci. Lett., Vol. 8, pp. 297-300, 1989.

Figures and Tables:

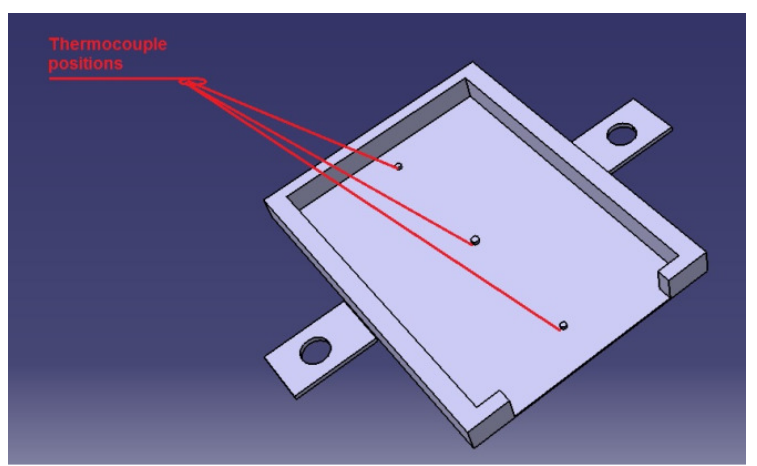

Fig. 1. Three $\mathrm{K}$ types' thermocouples.

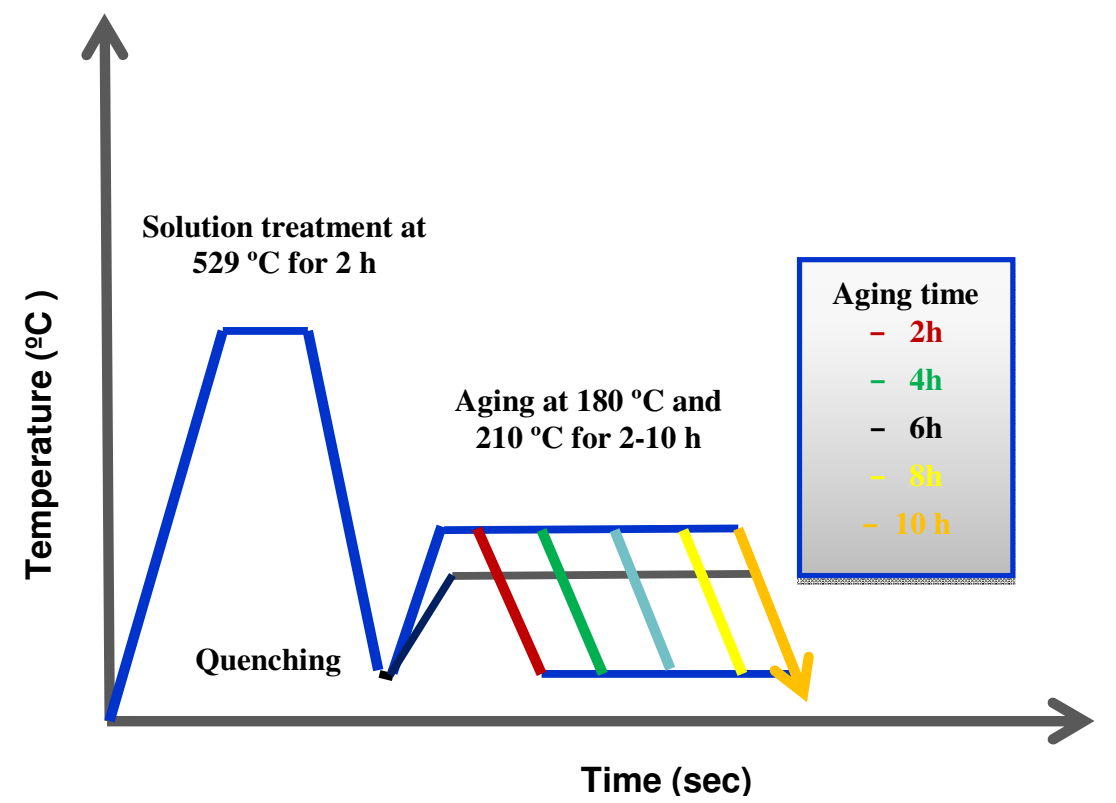

Fig.2. Solution treatment and aging procedure diagram.
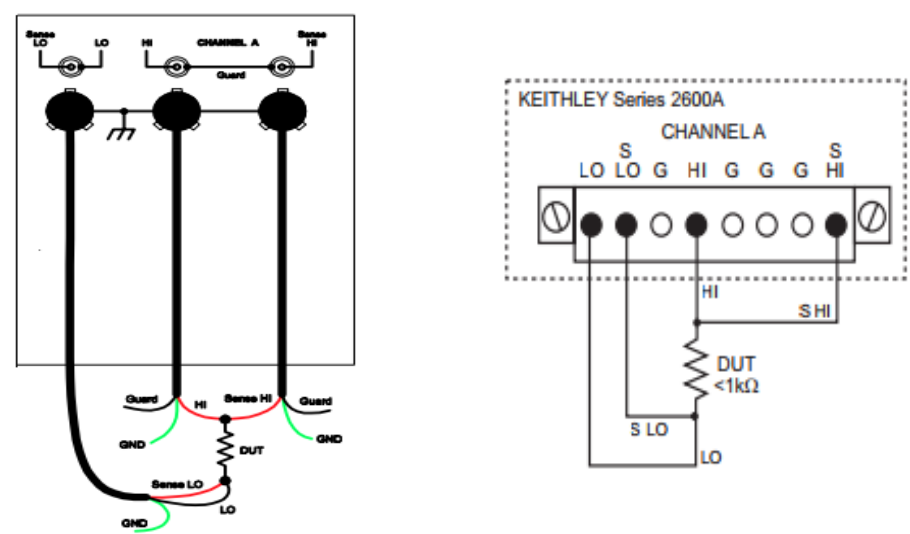

Fig. 3. Four wire remote sense connections. 


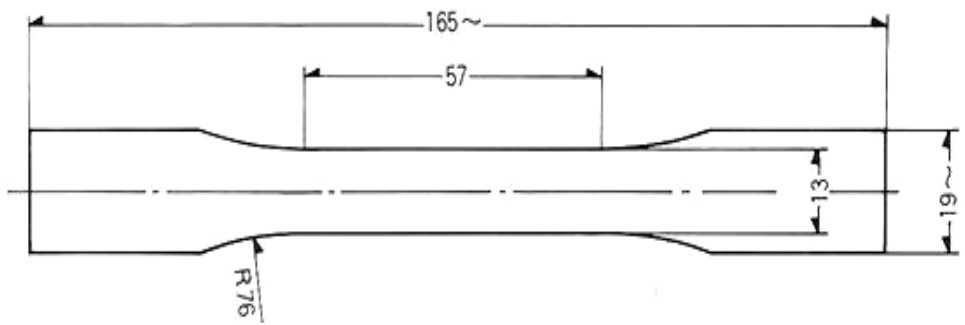

Fig. 4. Tension test specimen.

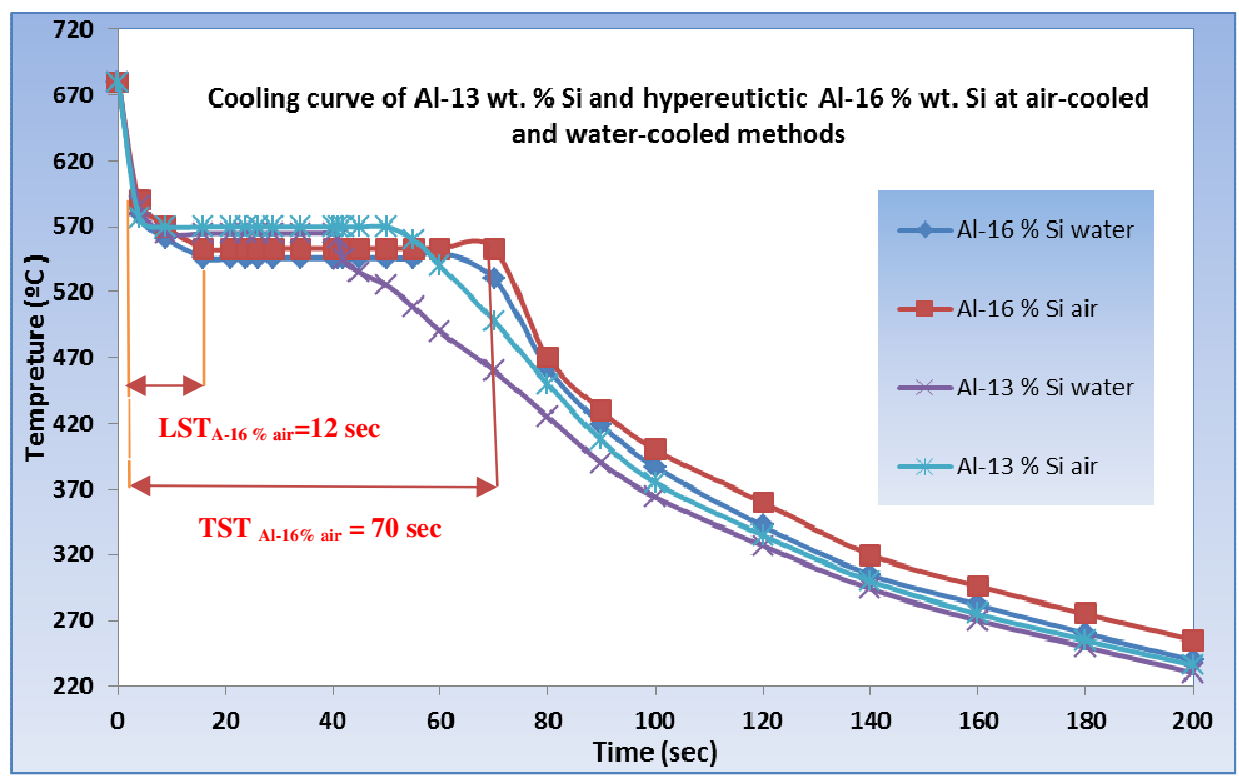

Fig. 5. Typical cooling curves of Al-Si alloys for water-cooled and aircooled mediums.

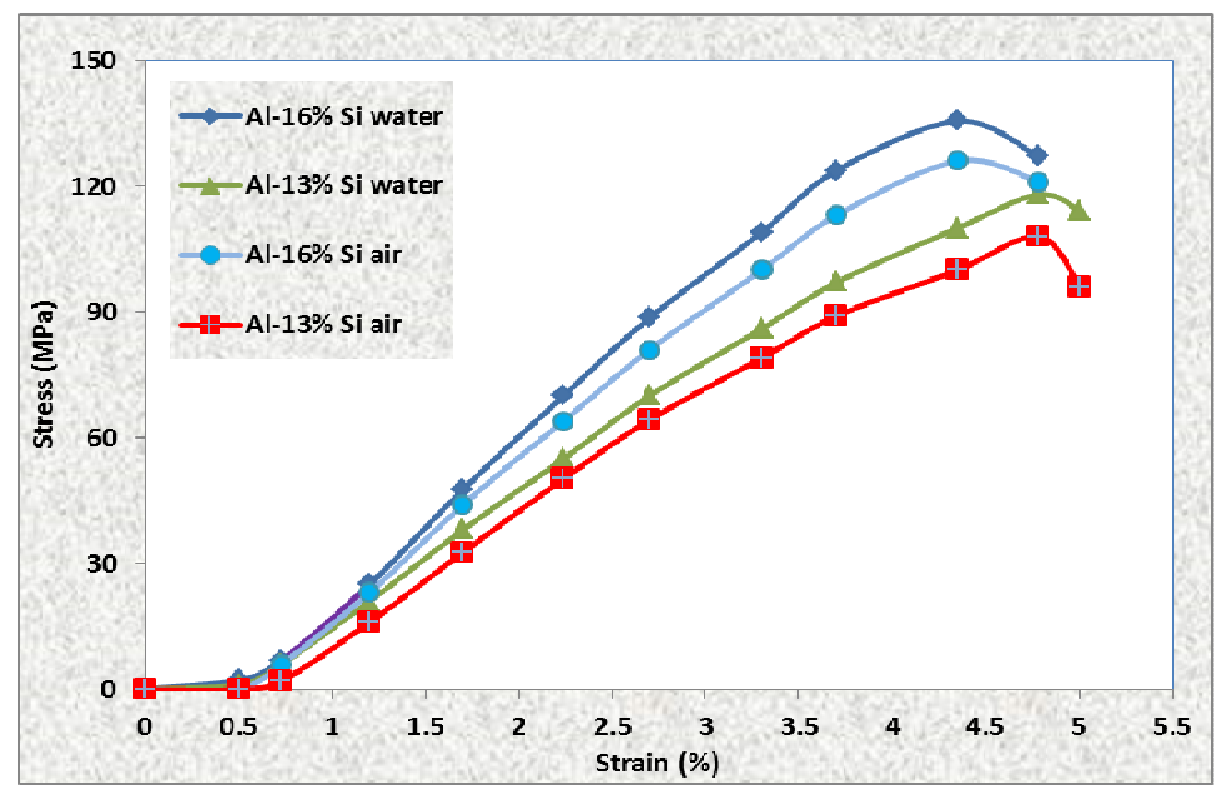

Fig. 6 Stress strain curves of Al-13 wt. \% Si and hypereutectic Al-16 wt. \% Si Allovs at various coolina mediums 


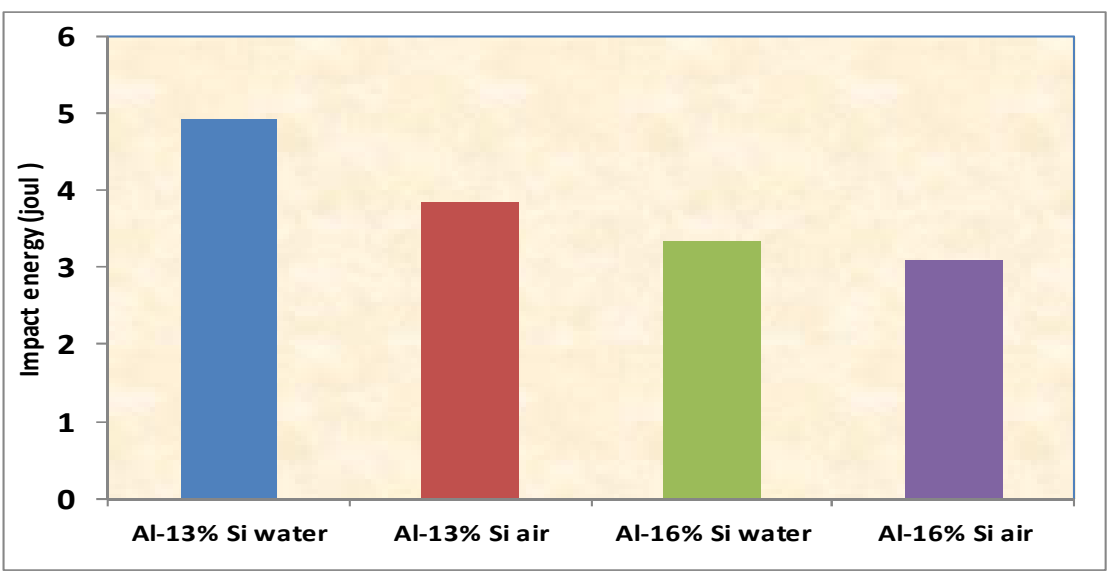

Fig. 7 Impact energy variation of Al-Si alloys for water and air-cooled
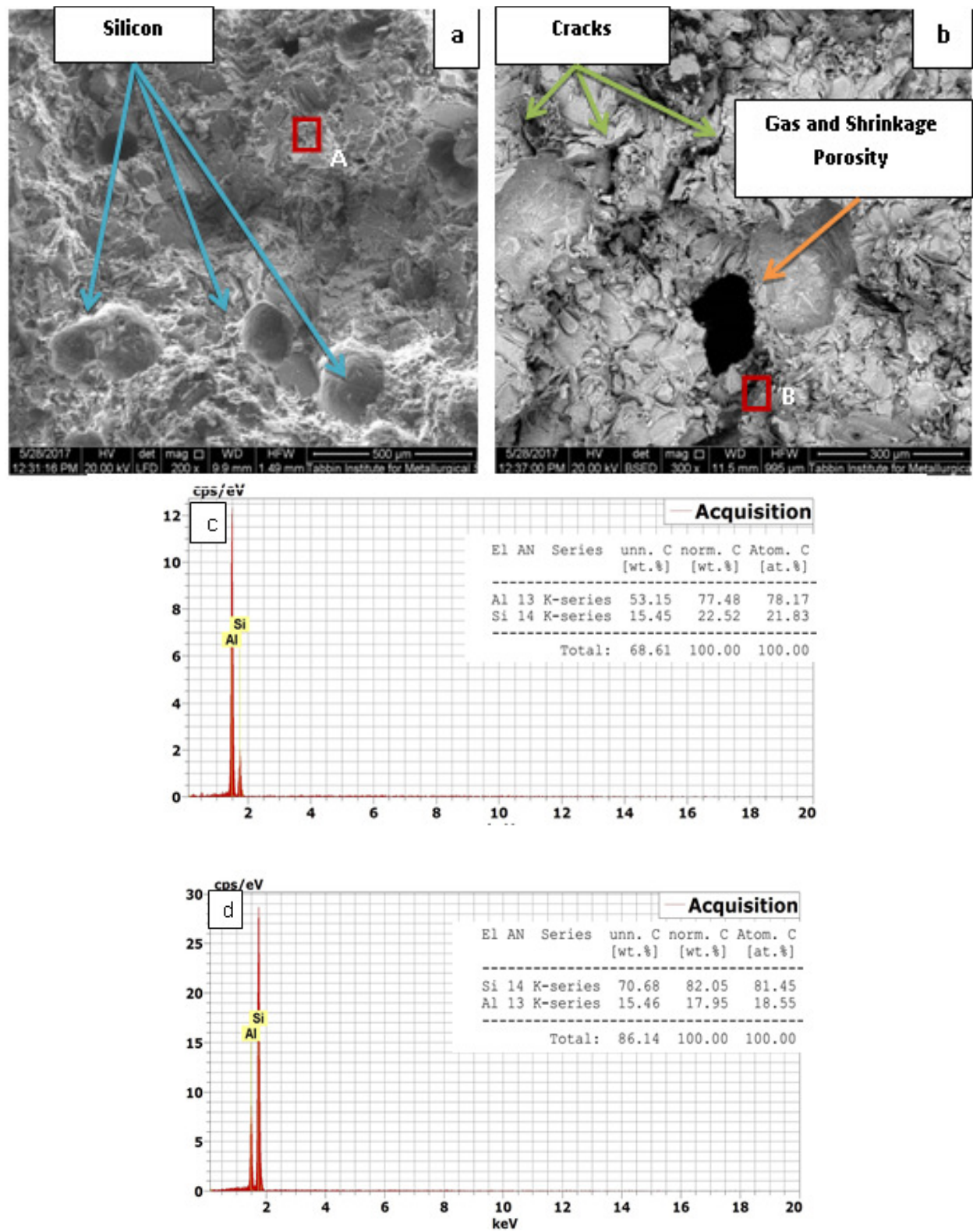

Fig.8 SEM micrographs of the eutectic Al- 13 wt. \% Si alloys at air-cooled method a) silicon crystals in Al matrix, b) existence of cavity and cracks, c) and d) elemental quantification by EDS analysis of point $A$ and point $B$. 

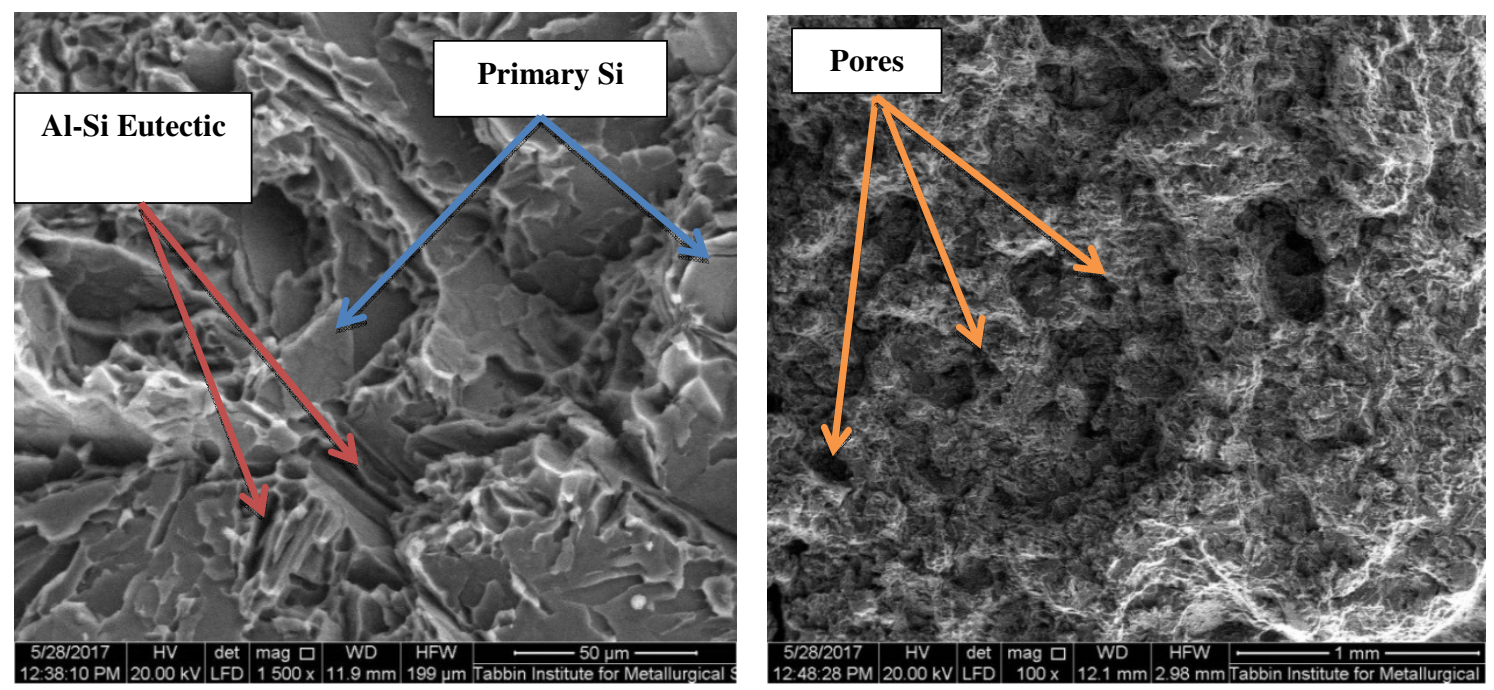

Fig. 9 SEM micrograph of the hypereutectic Al-16 wt. \% Si alloys at water-cooled method a) primary silicon in eutectic structure, b) small amount of pores
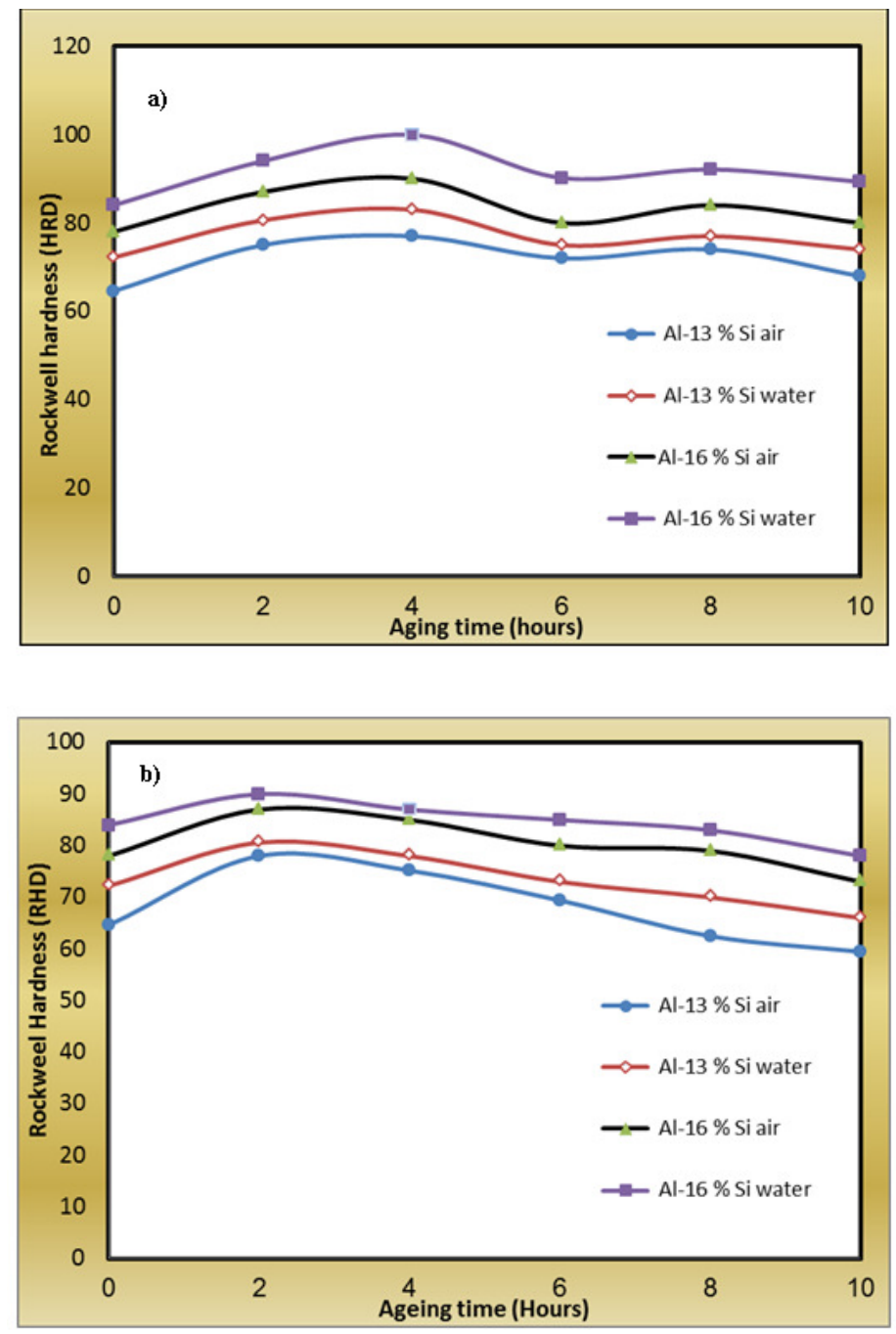

Fig. 10 Hardness variation with ageing time of A.L-13 Si and hypereutectic Al $16 \%$ Si at water and air-cooled medium a) at ageing temperature $180^{\circ} \mathrm{C}$, b) at ageing temperature $210^{\circ} \mathrm{C}$. 
Table 1. Chemical composition of the experimental AI-Si alloys.

\begin{tabular}{|c|c|c|c|c|c|c|}
\hline Alloy composition & $\mathrm{Cu}$ & $\mathrm{Si}$ & $\mathrm{Mg}$ & $\mathrm{Fe}$ & $\mathrm{Mn}$ & $\mathrm{Al}$ \\
\hline $\mathrm{Al}-13 \% \mathrm{Si}$ & 0.006 & 13 & 0.017 & 0.27 & 0.001 & Bal. \\
\hline $\mathrm{Al}-16 \% \mathrm{Si}$ & 0.008 & 16 & 0.019 & 0.29 & 0.002 & Bal. \\
\hline
\end{tabular}

Table 2. Density porosity and electrical conductivity measurements of Al-Si alloys.

\begin{tabular}{|c|c|c|c|c|c|c|}
\hline \multicolumn{2}{|c|}{$\begin{array}{c}\text { Specimen } \\
\text { composition /cooling } \\
\text { medium }\end{array}$} & $\begin{array}{l}\text { Theoretical } \\
\text { Density } \\
\left(\rho_{\mathrm{th}}\right)\end{array}$ & $\begin{array}{l}\text { Actual } \\
\text { density } \\
\left(\rho_{\mathrm{th}}\right)\end{array}$ & $\begin{array}{l}\text { Relative } \\
\text { density } \\
(\zeta) \\
\%\end{array}$ & $\begin{array}{c}\text { Porosity } \\
\text { wt. \% }\end{array}$ & $\begin{array}{c}\text { Electrical } \\
\text { conductivity } \\
(\mathrm{S} / \mathrm{m})\end{array}$ \\
\hline Al-13\% Si & \multirow{2}{*}{ Water } & 2.65 & 2.59 & 0.977 & 2.22 & $9.88 \times 10^{5}$ \\
\hline $\mathrm{Al}-16 \% \mathrm{Si}$ & & 2.58 & 2.55 & 0.988 & 1.17 & $8.86 \times 10^{5}$ \\
\hline $\mathrm{Al}-13 \% \mathrm{Si}$ & \multirow{2}{*}{ Air } & 2.65 & 2.57 & 0.969 & 3.10 & $9.24 \times 10^{5}$ \\
\hline Al-16\% Si & & 2.58 & 2.54 & 0.984 & 1.60 & $6.79 \times 10^{5}$ \\
\hline
\end{tabular}

Table 3. Mechanical properties of the eutectic and hypereutectic Al-Si alloys.

\begin{tabular}{|c|c|c|c|c|c|c|}
\hline \multicolumn{2}{|c|}{$\begin{array}{l}\text { Specimen composition } \\
\text { /cooling medium }\end{array}$} & $\begin{array}{c}\text { Yield } \\
\text { strength } \\
(\mathrm{MPa})\end{array}$ & $\begin{array}{c}\text { Tensile } \\
\text { strength } \\
(\mathrm{MPa})\end{array}$ & $\begin{array}{c}\text { Elastic } \\
\text { modulus } \\
(\mathrm{MPa})\end{array}$ & $\begin{array}{c}\text { Elongation } \\
(\%)\end{array}$ & $\begin{array}{c}\text { Hardness } \\
\text { (HRD) }\end{array}$ \\
\cline { 1 - 5 } $\mathrm{Al}-13 \% \mathrm{Si}$ & Water- & 70 & 118 & 26.40 & 4.35 & 72 \\
\cline { 1 - 5 } $\mathrm{Al}-16 \% \mathrm{Si}$ & cooled & 88.6 & 135.5 & 33.43 & 3.53 & 84 \\
\hline $\mathrm{Al}-13 \% \mathrm{Si}$ & \multirow{2}{*}{ Air-cooled } & 64.30 & 108 & 23.84 & 3.91 & 64 \\
\cline { 3 - 7 } $\mathrm{Al}-16 \% \mathrm{Si}$ & 81 & 126 & 29.88 & 3.10 & 78 \\
\hline
\end{tabular}

Table 4. The harness variation at aging temperature $180^{\circ} \mathrm{C}, 210^{\circ} \mathrm{C}$ and different aging times.

\begin{tabular}{|c|c|c|c|c|c|c|c|c|}
\hline \multirow{3}{*}{$\begin{array}{l}\text { Specimen } \\
\text { composition }\end{array}$} & \multirow{3}{*}{$\begin{array}{l}\text { Cooling } \\
\text { medium }\end{array}$} & \multirow{3}{*}{$\begin{array}{c}\text { Ageing } \\
\text { temperature }\end{array}$} & \multicolumn{6}{|c|}{ Hardness (HRD) } \\
\hline & & & \multirow{2}{*}{$\begin{array}{l}\text { Before } \\
\text { ageing } \\
0 h\end{array}$} & \multicolumn{5}{|c|}{ After ageing } \\
\hline & & & & $2 \mathrm{~h}$ & $4 \mathrm{~h}$ & $6 \mathrm{~h}$ & $8 \mathrm{~h}$ & $10 \mathrm{~h}$ \\
\hline \multirow{2}{*}{ Al-13 Si } & water & \multirow{4}{*}{$180^{\circ} \mathrm{C}$} & 72.2 & 81.65 & 83 & 75 & 77 & 74 \\
\hline & air & & 64.6 & 75 & 77 & 72 & 74 & 68 \\
\hline \multirow{2}{*}{ Al-16 Si } & water & & 84 & 94 & 99.9 & 90.2 & 92.1 & 89.3 \\
\hline & air & & 78 & 87 & 90 & 80 & 84 & 81 \\
\hline \multirow{2}{*}{ Al-13 Si } & water & \multirow{4}{*}{$210^{\circ} \mathrm{C}$} & 72.2 & 80.20 & 78 & 73 & 70 & 66 \\
\hline & air & & 64.6 & 78.2 & 75.2 & 69.4 & 62.3 & 59.47 \\
\hline \multirow{2}{*}{ Al-16 Si } & water & & 84 & 90 & 87 & 85 & 83 & 78 \\
\hline & air & & 78 & 86 & 85 & 77 & 79 & 73 \\
\hline
\end{tabular}

